\title{
DURABILITY ASSESSMENT OF SOFT CLAY SOIL STABILIZED WITH HALLOYSITE NANOTUBES
}

\author{
Masoud TAVAKOLIPOUR and Niloofar SALEMI *
}

Department of civil engineering, Isfahan (Khorasgan) Branch, Islamic Azad University, Isfahan, Iran

*Corresponding author's e-mail: n.salemi@khuisf.ac.ir

\section{ARTICLE INFO}

Article history:

Received 16 April 2021

Accepted 26 July 2021

Available online 9 November 2021

\section{Keywords:}

Soil Stabilization

Halloysite Nanotubes

Unconfined Compressive Strength

Wet/dry Durability

Freeze/thaw Durability

\begin{abstract}
In this study the compressive strength and durability of soft clay soil stabilized with halloysite nanotubes are investigated. Halloysite nanotubes are novel 1D natural nanomaterials which are widely used in reinforcing polymer, pollution remediation, and as nanoreactors for biocatalyst. The wide use of halloysite nanotubes is due to their high aspect ratio, appropriate mechanical strength, high thermal stability, nature-friendly and cost-effectiveness. However, the use of halloysite nanotubes as a stabilizing agent for improving the durability of soil is not clear. In this research, halloysite nanotubes was used in the amounts of $2 \%, 5 \%$ and $10 \%$ by the weight of dried soil. Unconfined compressive strength, wet/dry cycles and freeze/thaw cycles tests were performed to evaluate the strength and durability of stabilized soft clay soil. Experimental results showed that halloysite nanotubes considerably improves the compressive strength and durability of soft clay soil. The optimum amount of halloysite nanotubes for soil stabilizing in terms of compressive strength and durability was $5 \%$. The compressive strength of soft clay increased as much as $129 \%$ by applying $5 \%$ halloysite nanotubes. Also, the specimen containing $5 \%$ halloysite nanotubes showed the least strength loss after wet/dry and freeze/thaw cycles. The soil sample containing $5 \%$ halloysite nanotubes lost $20 \%$ of its initial compressive strength after 8 cycles of freezing and thawing, while the soil sample without any halloysite content lost $100 \%$ of its compressive strength after the same number of freezing and thawing. Based on the obtained results, the use of halloysite nanotubes in order to enhance the strength and durability of soft clay is strongly recommended.
\end{abstract}

\section{INTRODUCTTION}

Stabilization of soil is nowadays an inevitable process due to the poor quality of engineering properties of the soil. Soil stabilization is a technique of changing the characteristics of soil to enhance its performance for construction and engineering purposes (Deepak et al., 2021). The process of soil stabilization helps to achieve the required properties in a soil needed for the type of construction work (Andavan and Kumar, 2020). Chemical stabilization using deep mixing or grouting has been widely used for loose and soft soils (Zhang et al., 2020). For chemical stabilization, Portland cement can be used either to modify and improve the quality of the soil or to transform the soil into a cemented mass with increased strength and durability. Also, lime is used for chemical stabilization of fine-grained soil. All lime treated fine-grained soils exhibit decreased plasticity, improved workability and reduced volume change characteristics. However, not all soils exhibit improved strength characteristics. Fly ash is effective at stabilizing fine-grained soils for earthwork and paving operations. It increases compacted dry density and reduces the optimum moisture content (Ramaji, 2012; Zhang et al., 2020).
Generally, traditional stabilizers including lime, cement, gypsum, fly ash and zeolite are commonly used and their positive effects on soil characteristics such as increasing compressive strength, reducing swelling potential and enhancing durability of soil are well studied. Meanwhile some unsettled issues such as high cost of raw materials, huge energy consumption for production and carbon dioxide and nitrogen oxide emission are left, which are contrary to the requirements of sustainable developments (Zhang et al., 2020).

Today non-traditional materials including liquid polymers, lignin derivations, geopolymers, enzymes, resins, solid waste-based materials and other byproducts are introduced as new soil-stabilizers. These kinds of stabilizers attract strong attentions from engineering point of view and are going to be widely used owing to their potential of saving construction cost, effectiveness on soil parameters and recycling natural resources (in the case of waste-based materials and byproducts) (Zhang et al., 2020). On the other hand, recently nanotechnology has attracted considerable scientific interest due to the new potential uses of particles in nanometer scale. The nano-scale size of particles can result in dramatically 
improved properties compared to conventional grain size materials of the same chemical composition (Salemi and Behfarnia, 2013). Among all nanotechnology applications there is an emerging interest in the use of nanotechnology and nano-materials for a wide variety of geotechnical engineering applications including soil stabilization. This interest arises due to their high surface area to volume ratio, nature-friendly production procedure, abundance and fine particle size which are likely to provide positive effects on the physical and chemical properties of the soil (Emmanuel et al., 2019). Many researchers have investigated the geotechnical properties of coarsegrained and fine-grained soils stabilized with nanomaterilas. Persoff et al. studied the effects of using colloidal nano silica on the compressive strength of sand. They concluded that utilizing $30 \mathrm{wt} \%$ colloidal nano silica leads to considerable increase in the unconfined compressive strength (Persoff et al., 1999). The effect of adding various amounts of nano-clay to a sandy soil was assessed by Khalid et al. In their research nano-clay was used in the amounts of $0.5 \%$ to $5 \%$ by the weight of dry sand (Khalid et al., 2015). It was observed that after 7 days of curing, the CBR values and compressive strength of sand containing optimum amount of nano-clay increased as much as $25 \%$ and $22 \%$ respectively (Khalid et al., 2015). Lou et al. studied the effects of using nano-alumina on the mechanical properties of clay soil. They found out that the unconfined compressive strength of the clay specimens treated with $1 \%$ nano-alumina was 4.2 times higher than that of untreated samples (Lou et al., 2012). The results of utilizing nano-clay particles as a partial replacement of two kinds of silty soil including $\mathrm{MH}$ and $\mathrm{ML}$ showed that using nano-clay particles can considerably improve the compressive strength and California Bearing Ration values of silty soil. It was found that adding $1 \mathrm{wt} \%$ nano-clay to the silty soil leads to $77 \%$ increase in its CBR value (Lou et al., 2012). Emmanel et al. explored the possibility of stabilizing soft marine clay by adding halloysite nanotubes. They observed that using halloysite nano-tubes can considerably improves the characteristics of soft marine clay. Increase in unconfined compressive strength and decrease in hydraulic conductivity and plasticity index were the major effects of halloysite nanotubes. They illustrated that halloysite nanotubes effectively can be used as a stabilizing agent for soft marine clay (Emmanuel et al., 2019).

Although extensive research has been conducted on utilizing different nanomaterials for soil stabilization, little is known on the influence of halloysite nanotubes on the durability of soil (Emmanuel et al., 2019). In this paper an effort is taken to investigate the effects of using halloysite nanotubes on geotechnical parameters of clay soil. For this purpose, a variety of macro scale geotechnical tests including unconfined compressive strength, wet/dry durability and freeze/thaw durability were conducted on the halloysite nanotubes-stabilized clay soil.

\section{MATERIALS AND METHODS}

2.1. MATERIALS

2.1.1.SOIL

For this study clay soil samples were collected from Isfahan city located in Iran. Soil samples were taken from a depth of 0.25 to $2 \mathrm{~m}$ below the original ground level. The mentioned depth for sampling was determined in order to collect samples with relatively similar initial vertical effective stresses and also the results do not suffer from previous disturbance within the first $25 \mathrm{~cm}$ of the surface soil (The surface soil is often disturbed according to the weathering, traffic and etc.). In other words, it was tried to collect samples which did not disturbed before sampling. The obtained samples were bagged, labeled and transported to the laboratory for testing. The grain size distribution of the soil is illustrated in Figure 1. The soil type based on the Unified Soil Classification System and the compaction properties including optimum moisture content and maximum dry density of the base soil are illustrated in Table 1.

Table 1 Soil properties.

\begin{tabular}{lc}
\hline Liquid Limit (\%) & 117 \\
Plastic Limit (\%) & 52 \\
Plasticity Index (\%) & 65 \\
Soil Classification & $\mathrm{CH}$ \\
Maximum Dry Density $\left(\mathrm{g} / \mathrm{cm}^{2}\right)$ & 1.64 \\
Optimum Moisture Content $(\%)$ & 17 \\
\hline
\end{tabular}

\subsubsection{HALLOYSITE NANOTUBES}

Halloysite $\left(\mathrm{Al}_{2} \mathrm{Si}_{2} \mathrm{O}_{5}(\mathrm{OH})_{4} \cdot 2 \mathrm{H}_{2} \mathrm{O}\right)$ is a hydrated polymorph of kaolinite with a distinct naturally occurring tubular clay mineral (Emmanuel et al., 2019), where the layered $\left(\mathrm{SiO}_{4}\right)$ and $\left(\mathrm{ALO}_{6}\right)$ polyhedrons are arranged in a 1:1 style manner. Halloysite has a structure similar to kaolinite and in its tubular morphology has a length that varies from $500 \mathrm{~nm}$ to $1.2 \mu \mathrm{m}$ and diameter less than $100 \mathrm{~nm}$.

There are various kinds of halloysite nanotubes such as DG-Hal (Dragonite), MB-Hal (Matauri Bay), and UHP-Hal (UltraHallopure). According to previous studies, DG-Hal nanotubes has been shown to be more effective on soil properties rather than other kinds of halloysite nanotubes (Emmanuel et al., 2019). So, for this study DG-Hal was employed as halloysite nanotubes. DG-Hal nanotubes were purchased from Nanopars Company. The significant oxides of DG-Hal nanotubes obtained from XRF analysis are presented in Table 2. According to the previous studies on the use of nano materials in soil stabilization, these materials are often used in the amounts of $1 \%$ to $10 \%$ by the soil weight. So, in order to choose a similar range and to also confine the number of tests, it is decided to use $2 \%$ and $10 \%$ halloysite as the minimum and maximum percentage respectively. Also, $5 \%$ halloysite nanotubes incorporation was used in order to determine the trend of changes in soil properties by applying halloysite nanotubes. 


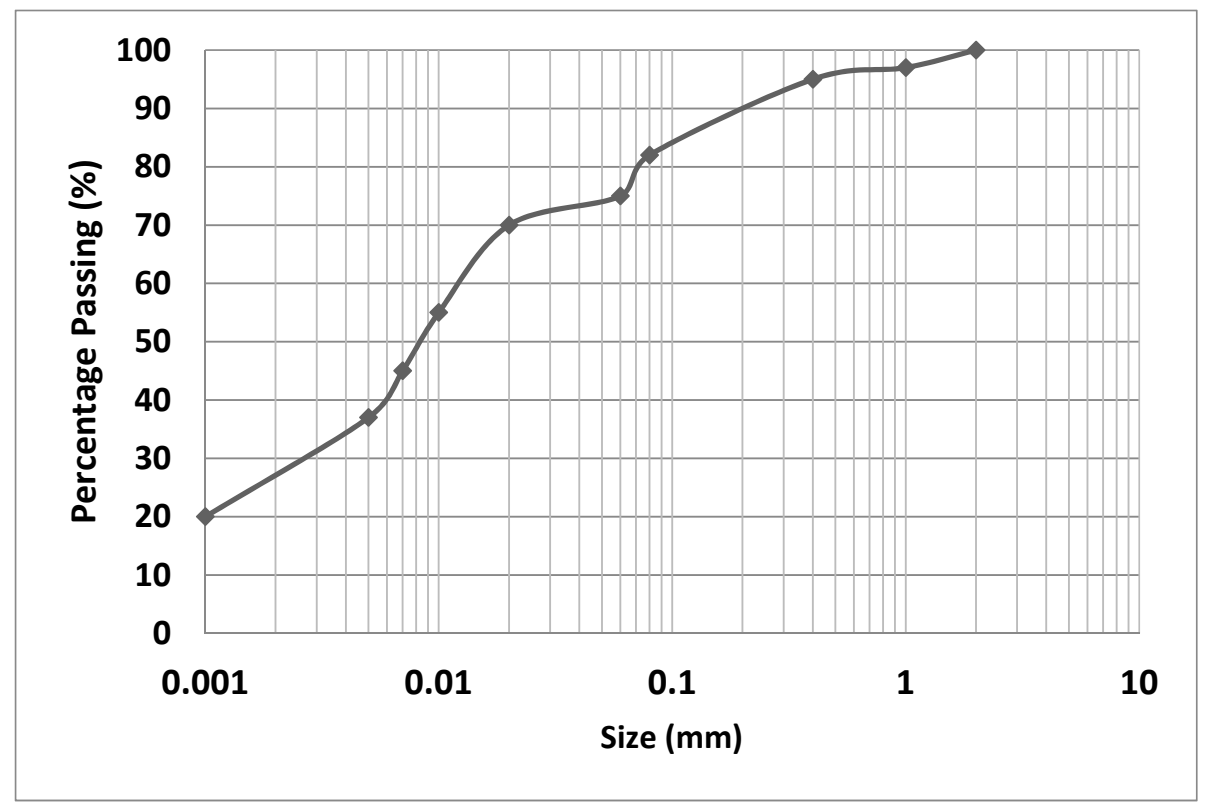

Fig. 1 Soil grain size distribution.

Table 2 Significant Oxides of DG-Hal Nanotubes (\%).

\begin{tabular}{ccccccccccc}
\hline $\mathrm{SiO}_{2}$ & $\mathrm{Al}_{2} \mathrm{O}_{3}$ & $\mathrm{Fe}_{2} \mathrm{O}_{3}$ & $\mathrm{CaO}$ & $\mathrm{Na}_{2} \mathrm{O}$ & $\mathrm{K}_{2} \mathrm{O}$ & $\mathrm{MgO}$ & $\mathrm{P}_{2} \mathrm{O}_{5}$ & $\mathrm{SO}_{3}$ & $\mathrm{TiO}_{2}$ & $\mathrm{LOI}$ \\
43.67 & 38.83 & 0.31 & 0.28 & 0.1 & 0.1 & 0.11 & 0.88 & 0.26 & 0.02 & 15.68 \\
\hline
\end{tabular}

\subsection{SAMPLE PREPARATION}

To reach the aim of this study, the soil samples were dried for 24 hours at $50{ }^{\circ} \mathrm{C}$ in an oven to reach a constant weight. After that the sieve analysis, Atterberg limits test and Proctor test were performed on soil samples and then 2 series of specimens were prepared: halloysite nanotubes stabilized specimens and untreated samples. In halloysite treated specimens, halloysite nanotubes were used in the amounts of $2 \%, 5 \%$ and $10 \%$ by the weight of dried soil. The reason for selection the mentioned range for halloysite incorporation was explained in section 2.1.2. The base soil was mixed with the stabilizer (halloysite nanotubes) in the dry state. The mixing process was prolonged for 10 min using an automatic mixer to obtain as homogenous a mixture as possible and to ensure the uniformity of the mixture (Emmanuel et al., 2019). The obtained stabilized soil was mixed with water. The amount of water was determined based on the optimum moisture content of the base soil obtained from Standard Proctor test conducted on untreated soil. Then the mixture was placed in cylindrical molds in three layers and for each layer static compaction was done by a steel rod (Emmanuel et al., 2019). All specimens were cured for 28 days under controlled condition in terms of temperature and humidity which were set to $20^{\circ} \mathrm{C}$ and $100 \%$ respectively. It should be noted that the mentioned soil sample (including halloysite treated samples and untreated samples) preparation method is one of the most practical methods for preparing soil samples containing dry powder (or granular) additives like cement, nanoparticles, fly ash, etc. which has been used for many years and it has been proved that the obtained samples are thoroughly uniform (Ramaji, 2012; Emmanuel et al., 2019; Zhang et al., 2020; Deepak et al., 2021). After samples preparation, geotechnical tests were conducted on treated and untreated soil to assess the operation of stabilizer.

\subsection{GEOTECHNICAL TESTS}

A series of laboratory experiments were conducted under controlled condition to determine the mechanical behavior and durability properties of the stabilized soil.

\subsubsection{STRENGTH TEST}

The unconfined compressive test was carried out on all specimens including halloysite nanotubes treated specimens and untreated samples according to ASTM 2166. For each mixture the unconfined compressive strength of six specimens was measured. The results are the average of all tests.

\subsubsection{DURABILITY TESTS}

Durability is defined as the resistance of geotechnical materials to weathering conditions such as freezing/thawing, wetting/drying, soaking and erosion. In this study two kinds of durability tests including wetting/drying and freezing/thawing were performed in order to evaluate the durability of treated soil samples because these two conditions are considered to be the most destructive actions that can help to damage the structure of the stabilized soil (Ahmed and Ugai, 2011). For this purpose, the specimens containing various amounts of stabilizer 


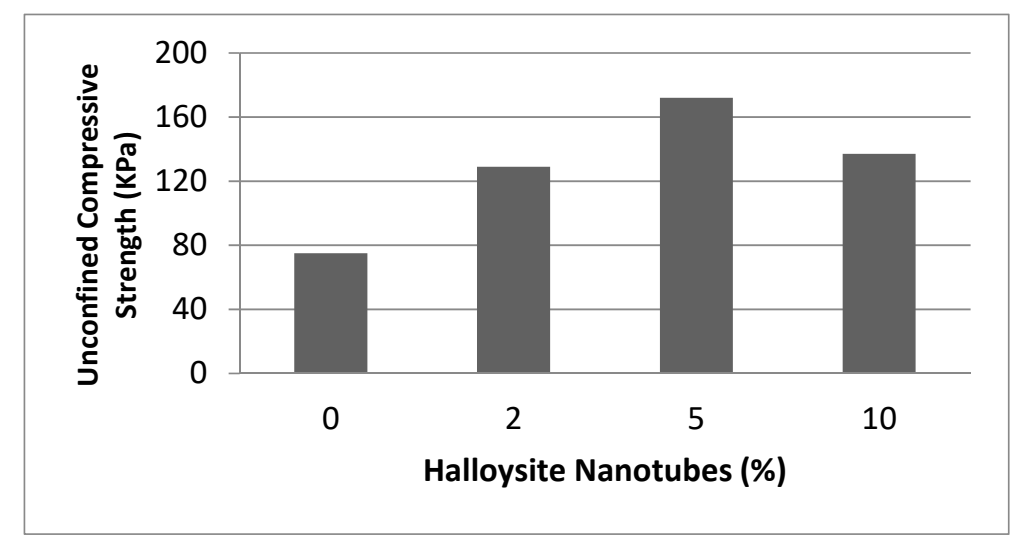

Fig. 2 Unconfined compressive strength of halloysite nanotubes treated samples.

(DG-Hal) were exposed to specific number of freezing/thawing or wetting/drying cycles and then tested for unconfined compressive strength.

Freeze and thaw test was conducted according to standard ASTM D560-3 and it included a $24 \mathrm{~h}$ freezing period in $-23{ }^{\circ} \mathrm{C}$ and a $24 \mathrm{~h}$ thawing period in $22{ }^{\circ} \mathrm{C}$ and $98 \%$ relative humidity. During the thawing period free portable was made to permit the specimen drawing up the water by capillary action. The freeze/thaw test conducted on 28-day cured samples (Ahmed and Ugai, 2011).

The wetting/drying cycles test followed the recommendations specified by ASTM D559. The samples were immersed in deionized water for $24 \mathrm{~h}$ at $20 \pm 2{ }^{\circ} \mathrm{C}$ for wetting cycle and then dried in the oven at the temperature of $60^{\circ} \mathrm{C}$ for $48 \mathrm{~h}$.

\section{RESULTS AND DISCUSSION}

\subsection{UNCONFINED COMPRESSIVE STRENGTH}

Figure 2 shows the results of unconfined compressive strength test on soil samples containing various amounts of halloysite nanotubes. For comparison the UCS of untreated soil sample is also shown in Figure 2. All UCS test were conducted on 28 days cured samples.

As it is illustrated in Figure 2, Halloysite nanotubes considerably improved the strength of soft clay soil in terms of unconfined compressive strength. The UCS of treated soil increased as much as $72 \%$ and $129 \%$ by adding $2 \%$ and $5 \%$ halloysite nanotubes respectively. The main reason for the UCS improvement of the halloysite nanotubes treated samples can be attributed to the compacted soil matrix. By adding halloysite nanotubes to the soft clay soil the contact force and interlock between the clay particles increase due to the nanotubes filling the voids, thus resisting the sliding between clay particles (increasing the UCS) (Emmanuel et al., 2019). This result is consistent to the previous researches (Emmanuel et al., 2019). Emmanuel et al investigated the feasibility of using halloysite nanotubes for marine clay stabilization and also for remediation of lead contamination. They concluded that both DG-Hal and
MB-Hal halloysite nanotubes can improve the unconfined compressive strength of clay soil. The improvement in the UCS of treated clay was significant up to $6 \% \mathrm{MB}-\mathrm{Hal}$ and DG-Hal contents. In their study, the percentage increase in the UCS values for MB-Hal and DG-Hal treated specimens after 14 days of curing at the optimum content were approximately $57 \%$ and $83 \%$, respectively, over the natural clay (Emmanuel et al., 2020). In Figure 2, it can be seen that the UCS of soft clay samples increased as the halloysite content increased up to $5 \%$ and then it decreased by increasing halloysite nanotubes content from $5 \%$ to $10 \%$. For instance, the UCS of soil sample increased from $75 \mathrm{KPa}$ to $172 \mathrm{KPa}$ when the halloysite content increased from $0 \%$ to $5 \%$ and then it decreased to $137 \mathrm{KPa}$ when $10 \%$ halloysite was employed, however the UCS of $10 \%$ halloysite nanotubes treated specimen was still higher than that of untreated sample. As it is mentioned before, the reason for the increase in compressive strength of soft clay samples containing $2 \%$ and $5 \%$ halloysite nanotubes is void filling characteristics of halloysite nanotubes which leads to higher contact forces between soil particles and also higher density of the soil. In other words, halloysite nanotubes make clay matrix more compacted. Higher density and more compacted matrix of the soil leads to higher compressive strength. According to Figure 2, when the halloysite content increased from $5 \%$ to $10 \%$, unconfined compressive strength decreased. The main reason which may cause a reduction in unconfined compressive strength when $10 \%$ halloysite was applied could be the agglomeration and defects generated in dispersion of nanotubes. As it is welldiscovered, nanomaterials have high surface area to volume ratio which leads to a high interparticle interaction energy and also high values of adhesive forces between adjacent nanoparticles. This phenomenon leads to the agglomeration. The agglomeration of nanomaterials reduces the potential enhancement of mechanical properties in nanocomposites such as halloysite nanotubes treated clay. This result is consistent to the results of previous 


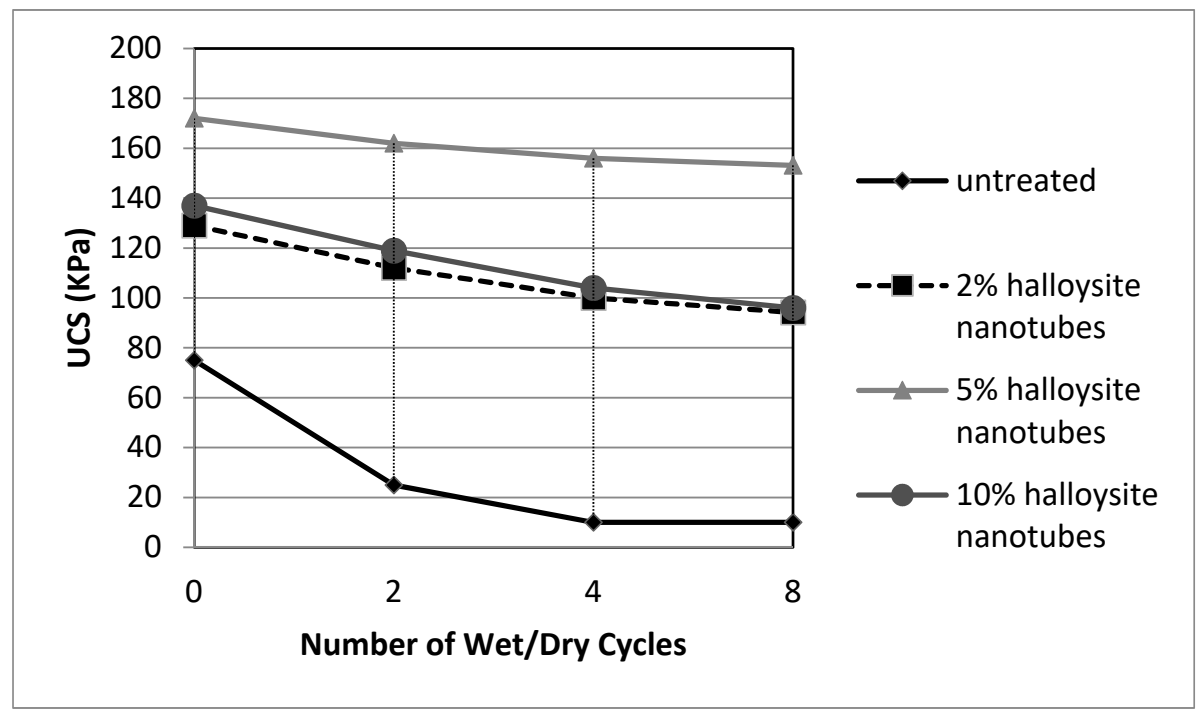

Fig. 3 Unconfined compressive strength of halloysite nanotubes treated samples after wet/dry cycles.

studies; Taha and Taha investigated the effects of adding various nanoparticles including nano-clay, nano-copper and nano-alumina on soil parameters such as mechanical properties. They concluded that nano-copper and nano-alumina have positive effects on soil parameters, but both mentioned nanoparticles have optimum values. In other words, with increasing nano-alumina and nano-copper content up to a certain percentage, the soil parameters improve and applying higher contents of nanoparticles degrade the soil parameters. They concluded that the addition of nano-materials more than the optimum value causes agglomeration of particles that produce negative side effects on the mechanical properties of the soil (Taha and Taha, 2012). In another study, Buazar tried to stabilize the subgrade soil using various amounts of nano-silica ranging from $0.5 \%$ to $2 \%$ by the weight of base soil. Maximum dry density, shear strength (cohesion and friction angle) and CBR were the soil parameters which were measured in his study. He showed that the addition of nanosilica stabilizer up to $1.5 \%$ provides the highest amount of the dry density, cohesion, friction angle and CBR value for the subgrade soil which is probably due to the appropriate replacement of nanosilica additive with air in soil pores. An increase in the weight of silica nanoparticles over an optimal of $1.5 \%$ leads to a decrease in the soil parameters as a result of the accumulation and agglomeration of silica (Buazar, 2019). It should be noted that using a high content of nanomaterials such as $10 \%$ (by the weight of base soil) must be accompanied by new mixing methods (which may be introduced in future and do not cause agglomeration) or using some dispersing agents (As it is well known, the agglomeration phenomenon happens in mixing nanoparticles with many materials such as soil, concrete and etc. In some fields like concrete containing nanoparticles, sometimes agents like formaldehyde are used in order to prevent agglomeration. This kind of agent is called dispersing agent. But for soil mixed with nanoparticles, effects of dispersing agent have not been investigated yet). According to Figure 2, it can be said that $5 \%$ halloysite nanotubes is the optimum amount for soft clay soil in terms of unconfined compressive strength.

\subsection{WET/DRY DURABILITY}

The unconfined compressive strength of clay samples stabilized with halloysite nanotubes exposed to various numbers of wetting and drying cycles is shown in Figure 3. It can be seen that the UCS of all samples reduced as the number of wet/dry cycles increased. The undesirable effects of wetting and drying cycles including the loss of compressive strength are due to the degradation of the soil structure caused by cyclic saturation and desiccation.

Figure 3 indicates that the UCS of untreated soil considerably decreased after 2 cycles of wetting and drying while halloysite nanotubes treated samples showed more durability against wetting and drying cycles. For better comparison, the percentage of decrease in the UCS of specimens after 8 cycles of wetting and drying is shown in Figure 4.

According to the Figures 3 and 4, it can be concluded that halloysite nanotubes considerably improved the wet/dry durability of soft clay. The percentage of strength loss in untreated soil after 8 cycles of wetting and drying was about $87 \%$ while the strength loss of soil sample containing $2 \%$ halloysite nanotubes was $27 \%$. The strength loss during wet/dry cycles decreased from $27 \%$ to $11 \%$ as the halloysite content increased from $2 \%$ to $5 \%$. The observed improvement in wet/dry durability of clay sample containing halloysite nanotubes, compared to that of untreated sample, can be related to two items; first is the change in the plasticity index of clay caused by nanotubes. It has been previously proved that halloysite nanotubes increases the plastic limit and 


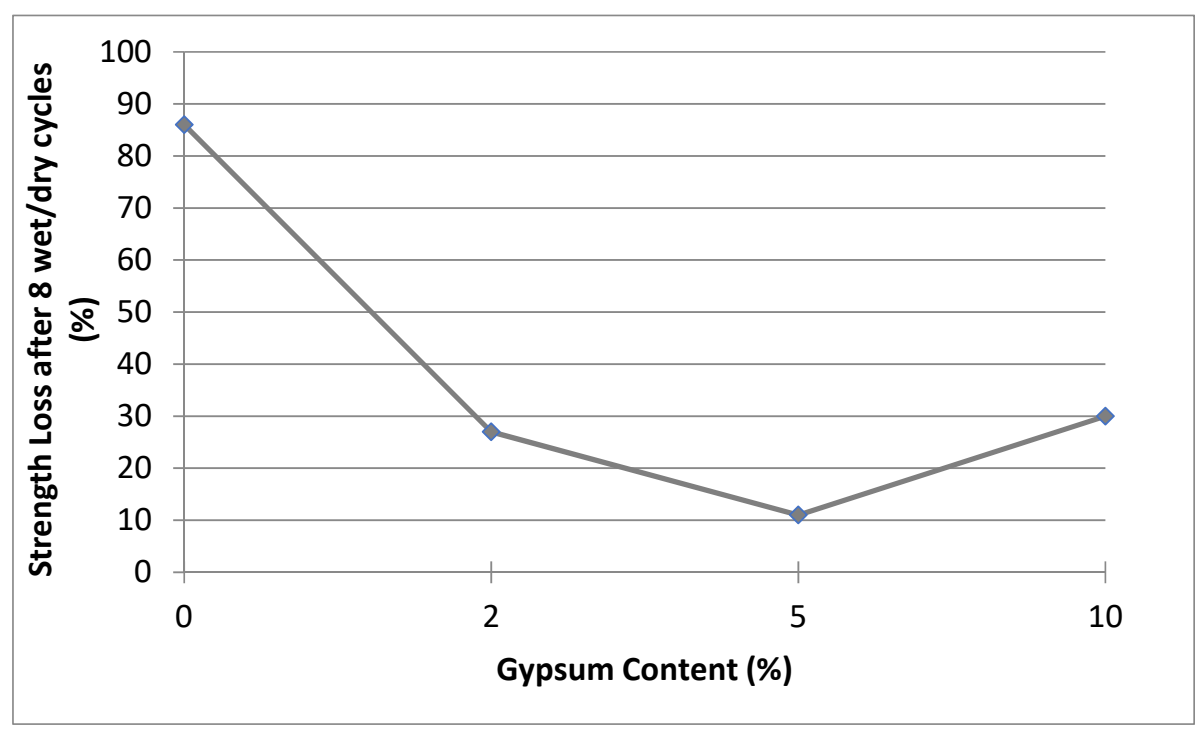

Fig. 4 Strength loss of halloysite nanotubes treated samples after 8 wet/dry cycles.

liquid limit of the clayey soil in a way that the plasticity index decreases (Mohammadi and Niazian, 2013; Emmanuel et al., 2019). The increase in the liquid limit and plastic limit of halloysite stabilized soil is due to the high specific surface area of the halloysite nanotubes which leads to more water encapsulating the outer surface of the soil particles (Emmanuel et al., 2019). Lower plasticity index leads to less water absorption during wetting cycle and consequently less degradation would occur in soil matrix during drying cycle. The second reason is the pore filling characteristic of nanomaterials which results in a lower water absorption in wetting cycle and less desiccation defects in drying periods. As it is mentioned before desiccation cracks causes soil degradation and strength loss. According to Figure 4, the strength loss during wet/dry cycles in clay sample containing $10 \%$ halloysite nanotubes was higher than that of other halloysite treated samples. This can be related to the agglomeration of nanomaterials and defects generated through this phenomenon.

\subsection{FREEZE-THAW DURABILITY}

The frost resistance of stabilized clay soil was evaluated by repeated freeze and thaw cycles. Loss of compressive strength after various numbers of freezing and thawing cycles was measured and is shown in Figure 5 and 6 for halloysite treated samples. It is evident in Figure 5 that the compressive strength of all specimens decreased with increasing the number of freezing and thawing cycles. The main cause of the strength loss during freeze/thaw cycles is the formation and growth of micro cracks due the effects of F/T actions (Shang et al., 2008); the degree of saturation of soil increases due to the water absorption and then during the freezing cycles the volume of the pore water increases due to the ice formation. The increase of the volume of the ice causes tensile stress on soil particles which in turn leads to the formation of micro cracks. As the number of freeze/thaw cycles increases, higher amounts of water reach to the existing micro cracks (compared to the previous cycles), which in turn leads to the generation and formation of numerous expansion micro cracks. Figure 6 illustrates that halloysite nanotubes incorporation caused a considerable improvement in frost durability. The untreated sample did not survive for compressive strength after 8 freeze/thaw cycles, while the strength loss of sample containing $2 \%$ halloysite was about $39 \%$. The strength loss of halloysite treated specimens decreased from $39 \%$ to $20 \%$ as the halloysite content increased from $2 \%$ to $5 \%$ and then it increased to $47 \%$ when $10 \%$ halloysite was applied. The improvement of frost durability of soft clay in case of halloysite incorporation can be due to the enhancement of the soil structure. Using appropriate amount of halloysite nanotubes results in a denser structure with less porosity, higher compressive strength and less water absorption compared to untreated clay. All mentioned consequences lead to less crack formation. As the water absorption of soil decreases, the volume changes due to the ice formation during freezing cycle decreases, inducing a lower level of tensile stress. On the other hand, the strength of soil has been improved due to the halloysite stabilization and the stabilized soil is expected to tolerate higher tensile stresses.

The main reason for rapid decrease in compressive strength for $10 \%$ halloysite treated sample during initial cycles of freezing and thawing can be attributed to the agglomeration of nanoparticles in case of applying high content. As it is mentioned before, using high content of nanomaterials in soil must be accompanied by new mixing methods or applying appropriate dispersing agent in order to ensure that no agglomeration would happen and 


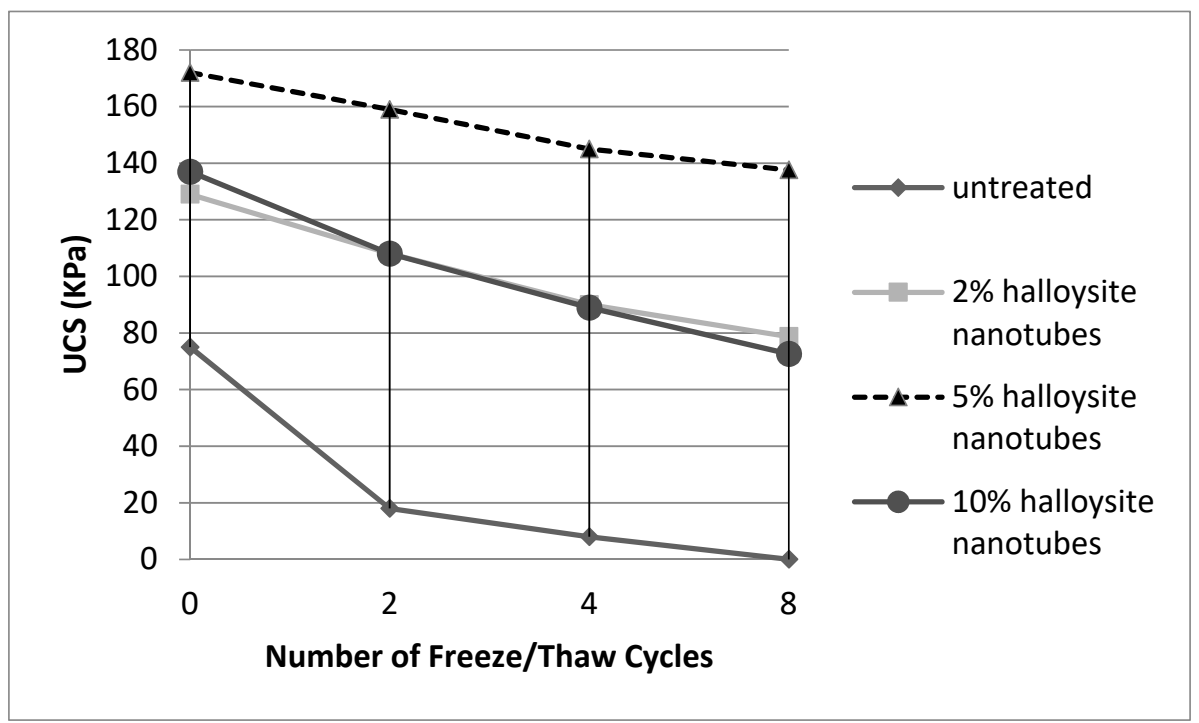

Fig. 5 Unconfined compressive strength of halloysite nanotubes treated samples after freeze/thaw cycles.

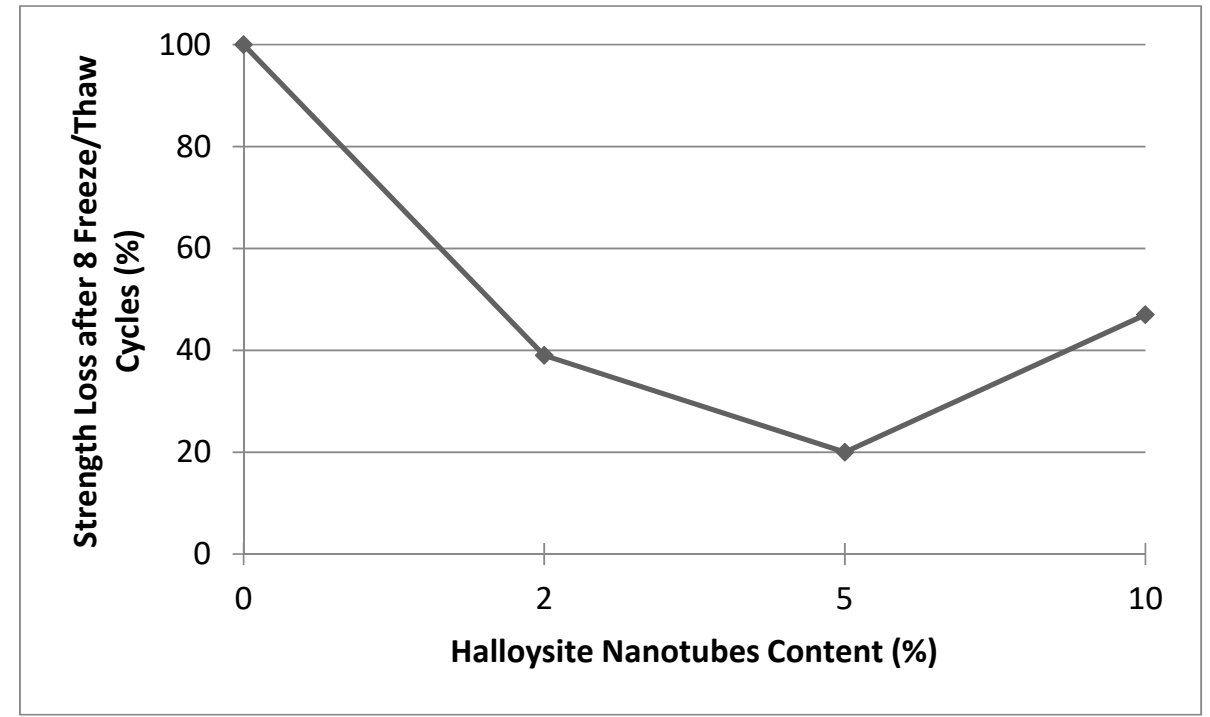

Fig. 6 Strength loss of halloysite nanotubes treated samples after 8 freeze/thaw cycles.

specimens do not suffer from discrepancy caused by agglomeration. The rapid reduction in compressive strength in initial cycles of freezing and thawing for clay samples containing $10 \%$ halloysite nanotubes proves that the main reason for deterioration is agglomeration and not the frost action. Generally, it can be said that the reduction in the compressive strength of treated and untreated soil is the result of change in soil structure, particles rearrangement and cracks generation.

Considering Figure 6, it can be concluded that the soil sample containing $5 \%$ halloysite nanotubes was the most durable sample against freezing and thawing. The mentioned sample showed only $20 \%$ strength loss after 8 cycles of $\mathrm{F} / \mathrm{T}$, while the reduction of strength after same numbers of $\mathrm{F} / \mathrm{T}$ cycles was $100 \%$ for untreated sample. As it is mentioned before, the improved durability against $\mathrm{F} / \mathrm{T}$ cycles in halloysite nanotubes treated samples can be attributed to the enhanced soil structure which leads to a higher resistance to the volume change and tensile stress.

By comparison the results of freeze/thaw durability test to those of wet/dry durability test, it can be concluded that the effects of freeze and thaw cycles on soil is more destructive than the effects of wet/dry cycles. This fact can be resulted from two items; the first item is that in wet/dry cycles, during wetting period, the soil specimen can gain additional indirect curing leading to an improvement in durability which cannot happen during freezing and thawing cycles. The second item is that during wet/dry cycles, there is no expansion of pore water while there is an induced expansion for existing pore water during freezing cycle (Ahmed and Ugai, 2011). Pore water expansion develops tensile stresses on soil particles and also causes a reduction in particles interlocking. This fact leads to the change in soil structure and reduces its compressive strength. 


\section{CONCLUSION}

In this study, the compressive strength and durability of soft clay soil stabilized with halloysite nanotubes as recently introduced stabilizer are investigated. Based on the results of the experiments, the following primary conclusion can be obtained:

1. The unconfined compressive strength of soft clay soil dramatically increased by halloysite nanotubes incorporation. The optimum content of halloysite in case of compressive strength was $5 \%$ that caused $129 \%$ increase in unconfined compressive strength. The main reason for the unconfined compressive strength improvement of the halloysite nanotubes treated samples can be attributed to the compacted soil matrix.

2. The wet/dry durability of soft clay enhanced valuably by adding halloysite nanotubes. The strength loss of $5 \%$ gypsum treated samples after 8 cycles of wet/dry was only $11 \%$, while the strength loss of untreated sample after the same number of wet/dry cycles was $87 \%$. The improvement in the wet/dry durability of halloysite nanotubes treated clay samples can be attributed to the change in the plasticity index of clay caused by nanotubes and also the filling characteristic of nanomaterials which results in a lower water absorption in wetting cycle and less desiccation defects in drying periods.

3. Halloysite nanotubes effectively improved the durability of soft clay soil against freeze/thaw cycles. The strength loss of $5 \%$ halloysite nanotubes treated samples after 8 cycles of freezing and thawing was only $20 \%$, while the untreated clay sample did not survive 8 freeze/thaw cycles (100\% strength loss). The improvement of frost durability of soft clay in case of halloysite incorporation can be due to the enhancement of the soil structure. Using halloysite nanotubes results in a denser structure with less porosity, higher compressive strength and less water absorption compared to untreated clay. All mentioned consequences lead to less crack formation.

4. The optimum percentage of halloysite nanotubes in all cases including compressive strength, wet/dry and freeze/thaw durability was $5 \%$ by the weight of dry soil.

5. The use of halloysite nanotubes in order to enhance the strength and durability of soft clay soil is strongly recommended.

\section{REFERENCES}

Ahmed, A. and Ugai, K.: 2011, Environmental effects on durability of soil stabilized with recycled gypsum. Cold Reg. Sci. Technol., 66, 2-3, 84-92. DOI: $10.1016 /$ j.coldregions.2010.12.004

Andavan, S. and Kumar, B.M.: 2020, Case study on soil stabilization by using bitumen emulsions- A review. Materials Today: Proceedings, 22, 3, 1200-1202. DOI: 10.1016/j.matpr.2019.12.121
Buazar, F.: 2019, Impact of biocompatible nanosilica on green stabilization of subgrade soil. Scientific Report, 9, 15147. DOI: 10.1038/s41598-019-51663-2

Deepak, M.S., Rohini, S., Harini, B.S. and Beulah Gnana Ananthi, G.: 2021, Influence of fly-ash on the engineering characteristics of stabilized clay soil. Materials Today: Proceedings, 37, 2, 2014-2018. DOI: 10.1016/j.matpr.2020.07.497

Emmanuel, E., Lau, C.C., Anggraini, V. and Pasbakhsh, P.: 2019, Stabilization of a soft marine clay using halloysite nanotubes: a multi scale approach. Appl. Clay Sci., 173, 65-78.

DOI: 10.1016/j.clay.2019.03.014

Emmanuel, E., Yong, L.L., Anggraini, V. and Pasbakhsh, P.: 2020, Can halloysite nanotubes be used to remediate zinc and lead-contaminated marine clay? A solidification/stabilization approach. Appl. Clay Sci., 186, 105441. DOI: 10.1016/j.clay.2020.105441

Khalid, N.F., Arshad, M.F., Mukri, M., Mohammad, K. and Kamarudin, F.: 2015, Influence of nano-soil particles in soft soil stabilization. Electron. J. Geotech. Eng., 20, 731-738.

Lou, H.L., Hsiao, D.H. and Lin, C.K.: 2012, Cohesive soil stabilized using sewage sludge ash/cement and nano aluminum oxide. Int. J. Transp. Sci. Technol., 1, 1, 8399. DOI: $10.1260 / 2046-0430.1 .1 .83$

Mohammadi, M. and Niazian, M.: 2013, Investigation of nano-clay effect on geotechnical properties of Rasht clay. Int. J. Adv. Sci. Tech. Res., 3, 37-46.

Persoff, P., Apps, J., Moridis, G. and Whang, J.M.: 1999, Effect of dilution and contaminants on strength and hydraulic conductivity of sand grouted with colloidal silica gel. J. Geotech. Geoenviron. Eng., 125, No. 6, 461-469. DOI: 10.1061/(ASCE)1090-0241(1999)125:6(461)

Ramaji, A.E.: 2012, A review on the soil stabilization using low cost methods. Appl. Sci. Res., 8, 2193-2196.

Salemi, N. and Behfarnia, K.: 2013, Effect of nano-particles on durability of fiber-reinforced concrete pavement. Constr. Build. Mater., 48, 934-941. DOI: 10.1016/j.conbuildmat.2013.07.037

Shang, H.S., Song, Y.P. and Qin, L.K.: 2008, Experimental study on strength and deformation of plain concrete under triaxial compression after freeze-thaw cycles. Build. Environ., 43, 7, 1197-1204. DOI: $10.1016 /$ j.buildenv.2006.08.027

Taha, M.R. and Taha, O.M.E.: 2012, Influence of nanomaterial on the expansive and shrinkage soil behavior. Nano. Res., 14, 1190. DOI: $10.1007 / \mathrm{s} 11051-012-1190-0$

Zhang, T., Liu, S., Zhan, H., Ma, C. and Cai, G.: 2020 , Durability of silty soil stabilized with recycled lignin for sustainable engineering materials. J. Clean. Prod., 248, 119293. DOI: 10.1016/j.jclepro.2019.119293 